\title{
The Development of Calculation Software for Parallel Composite Isolated System Based on MATLAB
}

\author{
Shaokang LI \\ School of Prospecting Technology and Engineering \\ Hebei GEO University \\ Shijiazhuang, P.R.China \\ e-mail: 729479957@qq.com
}

\author{
Xiuling CAO \\ School of Prospecting Technology and Engineering \\ Hebei GEO University \\ Shijiazhuang, P.R.China \\ e-mail: 295092204@qq.com
}

\begin{abstract}
The programming principle of calculation software for parallel composite isolated system and the superiority of the MATLAB over other advanced programming languages are expounded. Based on the above software, the seismic timehistory results of an example of parallel composite isolated system are calculated. Using MATLAB to develop the calculation program of parallel composite isolated system is convenient and is easy to realize the visualization of the calculation results, which is beneficial to engineering application.
\end{abstract}

Keywords-parallel composite vibration-isolation system; nonlinear time-history analysis; MATLAB; visualization

\section{INTRODUCTION}

As a hot spot in the field of civil engineering, the research and application of base isolated systems become more and more extensive [1]. At present, the commonly used base isolated technology at home and abroad is mainly divided into two categories that is the laminated rubber bearing isolated technology and the friction sliding isolated technology. But the new isolated systems and devices are also developed and used quickly. The developed software based on MATLAB in this paper is aimed at a new type of isolated system, which is supported by laminated rubber isolated bearings and friction sliding isolated bearings in parallel [2-4]. The developed software provided the data of some standard mechanical properties of rubber bearing and many commonly used seismic wave data applicable to the seismic analysis of traditional aseismic systems and the above isolated technologies under different sites and seismic intensities, which are open to technical engineers and can be added as needed. And moreover, the developed software is simple to operate, and it can be carried out visualized output.

\section{THE THEORETICAL BASIS OF SOFTWARE DESIGN IN THIS PAPER}

\section{A. Mechanical Model of Parallel Composite Isolated} System

At present, the commonly used calculation models of structural nonlinear time-history analysis include the story shear model, the story shear-bending model, the story torsion model and the space Beam-column elements model. The seismic response analysis of the isolated system generally uses the story shear model. This model assumes that the mass of each layer of the system, including upper and lower half-story walls and columns, are concentrated on each floor and roof; the whole system are composed of cantilever bars with lumped mass in each floor and roof elevation and the bottom is fixed; the beam stiffness is regarded as infinite and the column stiffness is the superimposition of the stiffness of each layer. So one isolated buildings with $n$ layers can be simplified as an $\mathrm{n}$ degree-of-freedom model. The motion differential equation can be expressed as:

$$
[M]\{\ddot{X}(t)\}+[C]\{\dot{X}(t)\}+[K]\{X(t)\}=-\{I\}[M]\left\{\ddot{X}_{g}(t)\right\}+\{F\}
$$

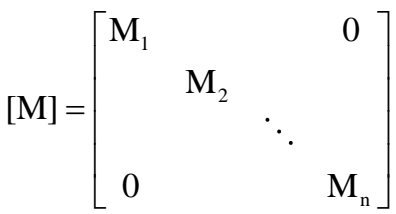

$[C]=\left[\begin{array}{cccc}\mathrm{C}_{1}+\mathrm{C}_{2} & -\mathrm{C}_{1} & & 0 \\ -\mathrm{C}_{1} & \mathrm{C}_{2}+\mathrm{C}_{3} & & \\ & & \ddots & -\mathrm{C}_{\mathrm{n}} \\ 0 & & -\mathrm{C}_{\mathrm{n}} & \mathrm{C}_{\mathrm{n}}\end{array}\right]$

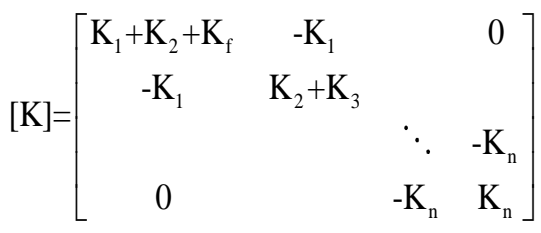




$$
\{\mathrm{F}\}=\left[\begin{array}{c}
-[I][M] \lambda \cdot \mu \cdot g \cdot \operatorname{sign}\left(\dot{x}_{0}\right) \\
0 \\
\vdots \\
0
\end{array}\right]
$$

where the parameters with subscript 1 correspond to the parallel composite isolated layer. $\{\dot{x}(t)\},\{\dot{x}(t)\}$ and $\left\{\ddot{x}_{g}\right\}$ are the displacement, velocity and acceleration relative to the ground motion of each layer, respectively; $\left\{\ddot{x}_{g}\right\}$ is the ground motion acceleration; $\{\mathrm{I}\}$ is the unit column vector; $[\mathrm{M}],[\mathrm{K}]$ and $[\mathrm{C}]$ are the mass, damping and stiffness matrix of parallel composite isolated system including the isolated layer; $\{\mathrm{F}\}$ is the sliding friction matrix; $K_{f}$ is the horizontal stiffness of the friction sliding bearings; $\lambda$ is the friction bearing ratio; $\mu$ is the friction coefficient of friction sliding bearings; the specific values of the parameters can be determined according to reference [2].

\section{B. Calculation Method for Nonlinear Time-history} Analysis of Parallel Composite Isolated System

The commonly used nonlinear time-history analysis methods include central difference method, Newmark- $\beta$ method and Wilson $-\theta$ method, etc. The developed software used in this paper is Newmark $-\beta$ method. The method of time-history analysis is applicable to any structure. The calculation model adopts multi-degrees-of-freedom interlayer shear model. The superstructure is generally not considered structure in elastic-plastic and the isolated layer can use the equivalent linearization model and bilinear model. The method of time history analysis can be used to obtain the detail displacement, velocity, acceleration, and shear force distribution of the isolated layer and the superstructure according to the layer stiffness and masses of the superstructure and the isolated layer.

\section{The Selection of Seismic Wave}

When we use time history analysis method to analyze seismic effect on the structure, it needs input the acceleration time history curve of seismic wave, and the different seismic wave will lead to significant different results. So reasonably selecting seismic wave to carry out direct dynamic analysis is critical for the credibility of calculation results. The commonly used seismic waves are generally including three categories: the proposed site of actual earthquake records; the well-known seismic records such as Elcentro NS wave, Taft wave, etc.; the artificial seismic waves. But it is also needed to take full account of the effects of ground motion's three elements, which is dynamic intensity, spectral characteristics and time duration [5].

\section{THE SOFTWARE DEVELOPMENT OF PARALLEL COMPOSITE ISOLATED SYSTEM BASED ON MATLAB}

\section{A. Summary of MATLAB}

MATLAB is a famous mathematical software integrated mathematical calculation, graphics processing and programming functions. It is first launched in 1984 by Mathworks Company.

Its outstanding characteristics are: it is oriented to matrix and need not pre-defined array; compared with the language of FORTRAN, the matrix operations of add, subtract, multiply, division can be realized easily, which is suitable for problems involving a large number of matrix operations especially; it gives a variety of efficient algorithm functions and powerful toolboxes for the specific problems in calculation mathematics; it can realize the data visualization graphics output quickly and easily [6].

\section{B. The Design Flow of the Software}

- 1) Enter the basic data files of the parallel composite isolated system, including the number of mass point, the mass of each layer, the layer stiffness, the damping coefficient and the parameters of $\lambda, \mu$.

- 2) Choose the time step $d t=0.02$, give the initial state of $x_{0}, \dot{x}_{0}, \ddot{x}_{0}$ at $t=0$, and calculate the stiffness matrix $[\mathrm{K}]$, the mass matrix $[\mathrm{M}]$ and the damping matrix [C].

- 3) Calculate the natural period and the corresponding mode shape of the parallel composite isolated system.

- 4) Input the data file of seismic wave. it is just needed to enter the name of the seismic wave in the seismic wave's database.

- 5) Judge the parameters of $\lambda$. If $\lambda=0$, the calculation of the laminated rubber isolated system and the traditional aseismic system are chosen; if $\lambda=1$, the calculation of friction sliding isolated system is chosen; if $0<\lambda<1$, the calculation of parallel composite isolated system is chosen.

- 6) Carry out the time history analysis and do loop of $\mathrm{ii}=0$, ii=ii+1. Using Newmark $-\beta$ method to calculate $x_{t+1}, \dot{x}_{t+1}$ and $\ddot{x}_{t+1}$ at the $t+d t$ moment.

- 7) Judge if there is stiffness mutation of the composite isolated layer. If there is, use the MATLAB interpolation function INTERP1 to calculate $x_{t+1}, \dot{x}_{t+1}$ and $\ddot{x}_{t+1}$ at the $t+d t$ moment until there is no mutation; otherwise, take $x_{t+1}, \dot{x}_{t+1}, \ddot{x}_{t+1}$ at the $t+d t$ moment as the initial state of the next step. Repeat the steps (6) to (7) until duration time of the chosen seismic wave is finished.

- 8) Output the results of time-history analysis and use the PLOT function imbedded in MATLAB to realize the visualization of the seismic time history responses. 


\section{THE ENGINEERING EXAMPLE}

The software is used to calculate a parallel composite isolation system with 7 degrees of freedom. The isolated layer is the first layer from the bottom. The superstructure has 6 layers .The friction bearing ratio takes 0.1 . The friction coefficient takes 0.1 . The damping ratio of superstructure is 0.05 and the damping ratio of the isolated layer is 0.1.The seismic intensity is 8 degree and the site type is the second category. The input seismic wave is Elcentro-NS wave. The duration time of earthquake is $10 \mathrm{~s}$ and the time interval is $0.02 \mathrm{~s}$. The peak of ground motion's acceleration is 341.7 $\mathrm{cm} / \mathrm{s} 2$. Table 1 gives the basic parameters of the parallel composite isolation system. Table 2 presents the calculation results of the period, the maximum displacement, and velocity and acceleration equivalent to 8 degree fortification seismic intensity. Figure 1 shows the visualization results of the seismic response of acceleration at the composite isolated layer.

TABLE I. PARAMETERS OF STRUCTURE

\begin{tabular}{cccccccc}
\hline Floor No. & 1 & 2 & 3 & 4 & 5 & 6 & 7 \\
\hline $\begin{array}{c}\text { Mass/ton } \\
\begin{array}{c}\text { Shear } \\
\text { stiffness/kN/mm }\end{array}\end{array}$ & 510 & 586 & 586 & 586 & 586 & 586 & 400 \\
damping ratio $^{\xi}$ & 0.05 & 0.05 & 0.05 & 0.05 & 0.05 & 0.05 & 0.05 \\
\hline
\end{tabular}

TABLE II. TIME History RESUlts (8 DEgREE ForTIFICATION INTENSITY)

\begin{tabular}{ccccc}
\hline Floor No. & $\begin{array}{c}\text { Period } \\
\text { /s }\end{array}$ & $\begin{array}{c}\text { The maximum } \\
\text { displacement } \\
\text { /mm }\end{array}$ & $\begin{array}{c}\text { The maximum } \\
\text { velocity } \\
\text { /cm/s }\end{array}$ & $\begin{array}{c}\text { The maximum } \\
\text { acceleration } \\
\text { /cm/s }\end{array}$ \\
\hline 1 & 1.662 & 1.4 & 0.442 & 29.74 \\
2 & 0.284 & 1.7 & 0.321 & 8.354 \\
3 & 0.510 & 1.9 & 0.288 & 5.438 \\
4 & 0.106 & 2.1 & 0.297 & 3.182 \\
5 & 0.086 & 2.3 & 0.294 & 4.356 \\
6 & 0.076 & 2.4 & 0.323 & 5.193 \\
7 & 0.071 & 2.5 & 0.355 & 5.542 \\
\hline
\end{tabular}

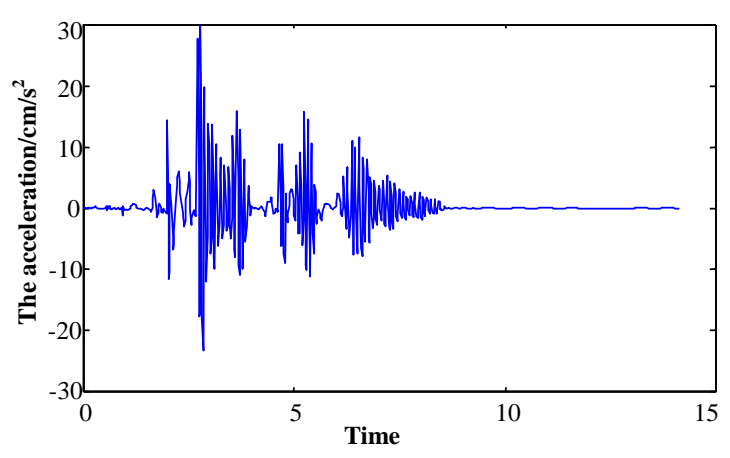

Figure 1. The seismic response of acceleration

\section{CONCLUSIONS}

(1) There is much software, such as SAP, ANSYS, Midas, etc., used for seismic response analysis of large-scale scientific computation at home and abroad, which help researchers to solve a lot of problems conveniently and quickly. But for the newly emerging structural forms and some special engineering problems, that software is not convenient to solve the calculation and analysis. As mentioned above, MATLAB is easy and simple to operate. Researchers can easily use a common numerical calculation function and matrix and array operation functions provided by MATLAB to improve work efficiency greatly and shorten the time of software writing and debugging. Moreover, when using MATLAB to write structural analysis software code, the matrix and array operations and other expressions are the same as the form of handwriting which people is familiar with, enhancing the readability of the program.

(2) Using MATLAB's two-dimensional drawing function PLOT, the time-history analysis results can be visualized easily, which can help researchers to directly and rapidly understand and grasp the objective laws of seismic response of each storey of the structure under earthquake action.

(3) The software developed here is simple and easy to learn, the help document is very detailed, and the calculation process is rapid and efficient. In addition, the software is open and researchers can enrich and improve its functions as needed.

\section{ACKNOWLEDGMENT}

The research was sponsored by the Scientific Key Program of Hebei GEO University (Grant No. KAG201602). China and Australia cooperation research projects (16394507D); Hebei overseas training project for excellent experts.

\section{REFERENCE}

[1] F. L. Zhou, G. H. Yu, Q. L. Xi, X. Z. Li, W. Wang, "New System of Vibration Control for Multi-Layer and High-rise Building," Engineering Earthquake Resistance. Beijing, issue.3, pp. 10-14, March 1994.

[2] Y. Yuan, S. B. Yang, X. Z. An, W. Sun, "Study on The Effect of Parallel Composite Isolated System," Building Technique Development. Beijing, vol. 30, issue.5 pp. 13-14, May 2002.

[3] Y. Yuan, A. Zhou, S. Yang, G. F. He, "Seismic Response and Hysteretic Performance Analysis of Parallel Composite Isolated Structure," Industrial Construction. Beijing, vol. 44, issue.1 pp. 29-33, January 2014.

[4] A. H. Zhou, Y. Yuan, X. L. Cao, W. Sun, "Simplified Analysis of Parallel Composite Isolation System Based on Equivalent Linearization Method," Industrial Construction. Beijing, vol. 45, issue.8 pp. 121-124, August 2015.

[5] Japan Earthquake Free Construction Association, "Introduction to Graphic Seismic Isolation Structure, " Science Press, OHM Press, 1998.

[6] Chapman, S. J, "MATLAB programming: English, " Science Press, 2011. 